\title{
Increased Cardiac Mortality in Women Compared with Men in Patients with Acute Myocardial Infarction
}

\author{
Ken KANAMASA $^{1)}$, Kinji ISHIKAWA ${ }^{2)}$, Takahiro HAYASHI ${ }^{2)}$, Shiro HoshIDA ${ }^{3)}$, Yoshio YAMADA ${ }^{3)}$, \\ Takahiko KAWARABAYASHI $^{4)}$, Masashi NAKA ${ }^{5)}$, Yoshiaki YOKOI $^{(6)}$, Mitsuo MATSUDA ${ }^{7)}$, \\ Iwao OGAWA $^{8)}$ and South Osaka Acute Coronary Syndrome Study Group
}

\begin{abstract}
Objective It has been reported that women with acute myocardial infarction (AMI) have a higher short-term mortality rate than men, but the reason is not known. The profile in relation to age, gender and risk factors was evaluated to compare AMI and unstable angina pectoris (UAP).

Methods Findings from $\mathbf{9 8 4}$ patients including $\mathbf{5 8 0}$ patients with AMI (129 women, 451 men) and 404 patients with UAP ( 131 women, 273 men) were analyzed by the South Osaka Acute Coronary Syndrome Study Group (SACS). The primary endpoint of the study was in-hospital death. The primary endpoints of interest (cardiac death) were fatal recurrent myocardial infarction, death from congestive heart failure, and sudden death.

Results Cardiac death during hospitalization within 30 days in AMI was higher in women than in men $(12.4 \%$ vs $6.7 \%, p<0.05)$. On the other hand, in UAP there was no significant difference between women and men $(1.5 \%$ vs $0.7 \%$, NS). The incidence of cardiac death in AMI was significantly higher for patients 75 years old and older $(\mathbf{1 9 . 0 \%})$ than for patients less than 55 years old $(4.2 \%)$, $55-64$ years old $(3.5 \%)$ and $65-74$ years old $(4.7 \%)$ ( $<<0.001$, respectively).

Conclusions Cardiac death was higher for women compared with men in patients with AMI. The worse prognosis for the AMI women patients was likely to be derived from less performance of percutaneous coronary intervention, and a high incidence of severe myocardial infarction. Further research should be focused on the analysis of various clinical backgrounds.

(Internal Medicine 43: 911-918, 2004)
\end{abstract}

Key words: acute myocardial infarction, unstable angina pectoris, gender

\section{Introduction}

In-hospital and long-term prognosis have been reported to be worse for women with acute myocardial infarction (AMI) than for men $(1,2)$. However, other studies have reported that there is no significant difference in the mortality rate between men and women (3-5). The profile in relation to age and gender to discriminate AMI and unstable angina pectoris (UAP) is unclear. Although there are many reports on AMI, the characteristics and outcome of women and men with UAP have been rarely investigated $(3,6,7)$. Hochman et al (6) reported that among patients with UAP women were associated with an independent protective effect. Thus, the effect of gender may be different between AMI and UAP. However, there are several differences between the Japanese and Western populations with regard to treatment. In Japan, thrombolysis is used less frequently, and balloon angioplasty and stenting are more common therapeutic strategies for acute coronary syndromes (ACS), which may lead to different outcomes in Japanese patients. Therefore, we investigated the clinical outcome for Japanese patients among patients with ACS.

\section{Methods}

\section{Subjects}

One thousand and twenty patients were prospectively enrolled in this study. Thirty-six patients were excluded because of insufficient medical records. Finally, we analyzed

\footnotetext{
From ${ }^{11}$ the Department of Vascular and Geriatric Medicine, ${ }^{2}$ the Department of Cardiology, Kinki University School of Medicine, Osakasayama, ${ }^{3}$ Osaka Rosai Hospital, Sakai, ${ }^{4}$ Baba Memorial Hospital, Sakai, ${ }^{5}$ Osaka Minami National Hospital, Kawachinagano, ${ }^{6}$ Kishiwada Tokushukai Hospital, Kishiwada, ${ }^{7}$ Kishiwada City Hospital, Kishiwada, ${ }^{8}$ Shiroyama Hospital, Habikino and South Osaka Acute Coronary Syndrome Study Group Received for publication December 10, 2003; Accepted for publication June 10, 2004

Reprint requests should be adressed to Dr. Ken Kanamasa, the Department of Vascular and Geriatric Medicine, Kinki University School of Medicine, 377-2 Ohno-Higashi, Osakasayama, Osaka 589-8511
} 
data from 984 patients: 580 patients with first AMI (129 women, $451 \mathrm{men}$ ) and 404 patients with UAP (131 women, 273 men) between February 2001 and January 2002. This study included 23 different hospitals in South Osaka area (South Osaka Acute Coronary Syndrome Study Group; SACS). The electrocardiographic criteria included ST elevation or depression of more than $0.5 \mathrm{~mm}$ in 2 or more contiguous leads. Patients with AMI within 7 days after onset were included in this study. AMI was considered to have occurred if the level of creatine kinase MB isoenzyme was above normal. When the creatine kinase MB level had not been measured, then the total creatine kinase level needed to be more than twice the upper limit of the normal range. Diagnosis of UAP depended on the presence of one or more of the following three historical features: 1) new angina of effort of less than 1 month's duration, 2) a changing pattern, 3) new angina at rest (8).

\section{Data collection}

Data were collected at the time of admission and during the hospital period through direct patient interviews and medical record reviews. Prior to cardiac catheterization, coronary thrombolysis, percutaneous coronary intervention, and coronary artery bypass grafting (CABG), the purpose, methods, and risk were explained. Written informed consent for the procedures was obtained from the patients. All inhospital data without the patient's full name and hospital ID number were transmitted to the SACS office located at the Department of Cardiology, Kinki University. Therefore, analysis at the SACS office could not specify the patients. Final diganoses were assigned after review of the patients' medical records and data collection forms by participating physician investigators at each study site. Outcome of patients at 30 days of onset was analyzed at the hospital participating in this study. The primary end-point of the study was in-hospital death. The primary end points of interest (cardiac death) were fatal recurrent myocardial infarction, death from congestive heart failure and sudden death. Recurrent myocardial infarction had to fulfill the same criteria as the qualifying myocardial infarction for patient enrollment. Diagnosis of congestive heart failure was made from characteristic signs and symptoms compatible with congestive heart failure with or without echocardiographic, roentgenographic, and hemodynamic evidence of heart failure. Diagnosis of death from congestive heart failure was established when cause of death was directly attributed to congestive heart failure. Sudden death, in accordance with Braunwald's definition (9) was defined as death occurring unexpectedly with no premonitory symptoms or with symptoms lasting no longer than one hour. Non-cardiac death was defined as death by cerebrovascular injury, cancer, pneumonia, or other various extacardiac disorders. Diagnosis of death from non-cardiac death was established by clinical features, $\mathrm{X}$-ray findings and other various clinical diagnostic findings.

The clinical characteristics of the population in each period were assessed for prevalence of gender, age, hyper- lipidemia, hypertension, smoking, diabetes mellitus, obesity. ST elevation of electrocardiogram, Killip class, procedure of coronary angiography, coronary thrombolysis, percutaneous coronary intervention and CABG. Risk factors determined included the following: current smoking, hypertension (treatment with antihypertensive medication or documented blood pressure $\geqq 140 \mathrm{mmHg}$ systolic or $\geqq 90 \mathrm{mmHg}$ diastolic before admission), diabetes mellitus (treatment with antidiabetic drugs or diagnosis of diabetes during hospital stay), history of myocardial infarction or angina pectoris. Obesity was defined as body mass index $\geqq 25 \mathrm{~kg} / \mathrm{m}^{2}$. Hyperlipidemia was defined as fasting total cholesterol $\geqq 220 \mathrm{mg} / \mathrm{dl}$, fasting triglycerides $\geqq 150 \mathrm{mg} / \mathrm{dl}$, or antilipidemic therapy.

\section{Statistical analysis}

Results are expressed as mean \pm standard deviation. We compared the baseline characteristics and clinical outcomes between women and men. Subjects were grouped on the basis of sex and age. We report here the results based on an analysis that included all patients. Statistical testing was performed using the chi-square test for categorical variables and unpaired t test or one-way ANOVA for continuous variables. For each relative risk, we calculated the odds ratio and $95 \%$ confidence interval (10).

To assess the possible modifying effects of patients characteristics, subgroup analyses were performed within a strata of all 14 variables. Multivariate analysis was performed by Cox hazard models. P values were two sided. A p value less than 0.05 was considered statistically significant.

\section{Results}

\section{Baseline characteristics at onset}

The women were older than the men in AMI $(72 \pm 11$ years vs $65 \pm 11$ years, $\mathrm{p}<0.001)$ and in UAP $(68 \pm 11$ years vs $65 \pm$ 11 years, $\mathrm{p}<0.01$ ) (Table 1). The women had a lower rate of smoking in both AMI and UAP (AMI: $25.4 \%$ vs 64.0\%, $\mathrm{p}<0.001$, UAP: $33.3 \%$ vs $64.2 \%, \mathrm{p}<0.001$ ), and a higher rate of obesity in both AMI and UAP (AMI: $29.1 \%$ vs $18.7 \%$, p<0.01, UAP: $33.3 \%$ vs $24.0 \%$, p<0.05). The women had a lower rate of history of angina pectoris in AMI $(23.9 \%$ vs $34.3 \%, \mathrm{p}<0.05)$, and a lower rate of Killip class than the men in AMI $(64.3 \%$ vs $76.9 \%, \mathrm{p}<0.01)$. Percutaneous coronary intervention was performed less frequently in the women than in the men in AMI (61.9\% vs $70.9 \%, \mathrm{p}<0.05)$, but not in UAP $(43.2 \%$ vs $48.0 \%$, NS). CABG was performed less frequently in the women than in the men in AMI $(6.0 \%$ vs $7.6 \%, \mathrm{p}<0.05)$, but not in UAP (12.9\% vs $13.3 \%$, NS). Two hundred twenty-one patients $(52.9 \%)$ were admitted to the hospital within 3 hours after onset of AMI.

\section{Profile of onset of AMI and UAP patients}

The gender ratio used to evaluate the incidence of AMI and UAP was expressed as the number of the men divided by the total number of the men and the women (Fig. 1). The gender ratio was higher in AMI than UAP in those less than 
Mortality of Acute Myocardial Infarction

Table 1. Clinical Characteristics

\begin{tabular}{|c|c|c|c|c|}
\hline & AMI Men & AMI Women & UAP Men & UAP Women \\
\hline $\mathrm{n}$ & 451 & 129 & 273 & 131 \\
\hline Age (years) & $65 \pm 11$ & $72 \pm 11 * * *$ & $65 \pm 11^{\dagger+\dagger}$ & $68 \pm 11 * * * \$ \$$ \\
\hline Infarct site (anterior) & $47.8 \%$ & $47.2 \%$ & & \\
\hline Time from onset to admission & $10.6 \pm 29.0$ & $10.6 \pm 29.4$ & & \\
\hline \multicolumn{5}{|l|}{ Risk factors } \\
\hline Hyperlipidemia & $40.1 \%$ & $50.0 \% *$ & $40.9 \%$ & $48.5 \%$ \\
\hline Hypertension & $52.9 \%$ & $60.4 \%$ & $57.7 \%$ & $62.9 \% *$ \\
\hline Smoking & $64.0 \%$ & $25.4 \% * * *$ & $64.2 \%$ & $33.3 \% * * * \$ \$ \S$ \\
\hline Diabetes mellitus & $32.3 \%$ & $28.4 \%$ & $29.7 \%$ & $37.1 \%$ \\
\hline Obesity & $18.7 \%$ & $29.1 \% * *$ & $24.0 \%$ & $33.3 \% * * * \$$ \\
\hline History of MI & $11.9 \%$ & $6.7 \%$ & $14.7 \%$ & $12.9 \%$ \\
\hline History of AP & $34.3 \%$ & $23.9 \% *$ & $40.1 \%$ & $47.7 \% * * *+1$ \\
\hline ST elevation & $78.7 \%$ & $78.4 \%$ & $9.7 \% * * * t+\dagger$ & $9.8 \% * * * \omega+\dagger$ \\
\hline Killip (I) & $76.9 \%$ & $64.3 \% * *$ & $99.6 \% * * * *+\dagger$ & $99.1 \% * * * \ldots+\dagger$ \\
\hline CAG $(+)$ & $82.4 \%$ & $78.4 \%$ & $78.1 \%$ & $75.8 \%$ \\
\hline $\mathrm{CT}(+)$ & $18.4 \%$ & $17.2 \%$ & $1.4 \% * * * *+\dagger$ & $0.8 \% * * * \omega t \dagger$ \\
\hline PCI (+) & $70.9 \%$ & $61.9 \% *$ & $48.0 \% * * * \dagger$ & $43.2 \% * * *{ }^{\dagger \dagger}$ \\
\hline CABG $(+)$ & $7.6 \%$ & $6.0 \% *$ & $13.3 \%$ & $12.9 \%$ \\
\hline MI onset during hospitalization & $4.8 \%$ & $5.2 \%$ & $0.4 \% * * *+\dagger$ & $0.8 \% *^{\dagger}$ \\
\hline
\end{tabular}

AMI: Acute myocardial infarction, UAP: Unstable angina pectoris, CAG: Coronary angiography, CT: Coronary thrombolysis, PCI: Percutaneous coronary intervention, CABG: Coronary artery bypass grafting.

$* \mathrm{p}<0.05, * * \mathrm{p}<0.01, * * * \mathrm{p}<0.001$, vs AMI Men

${ }^{\dagger} \mathrm{p}<0.05,{ }^{\dagger \dagger} \mathrm{p}<0.01,{ }^{\dagger \dagger} \mathrm{p}<0.001$, vs AMI Women

${ }^{\S} \mathrm{p}<0.05,{ }^{\S s} \mathrm{p}<0.01,{ }^{\$ s} \mathrm{p}<0.001$, vs UAP Men

$\mathrm{m} \pm \mathrm{SD}$.

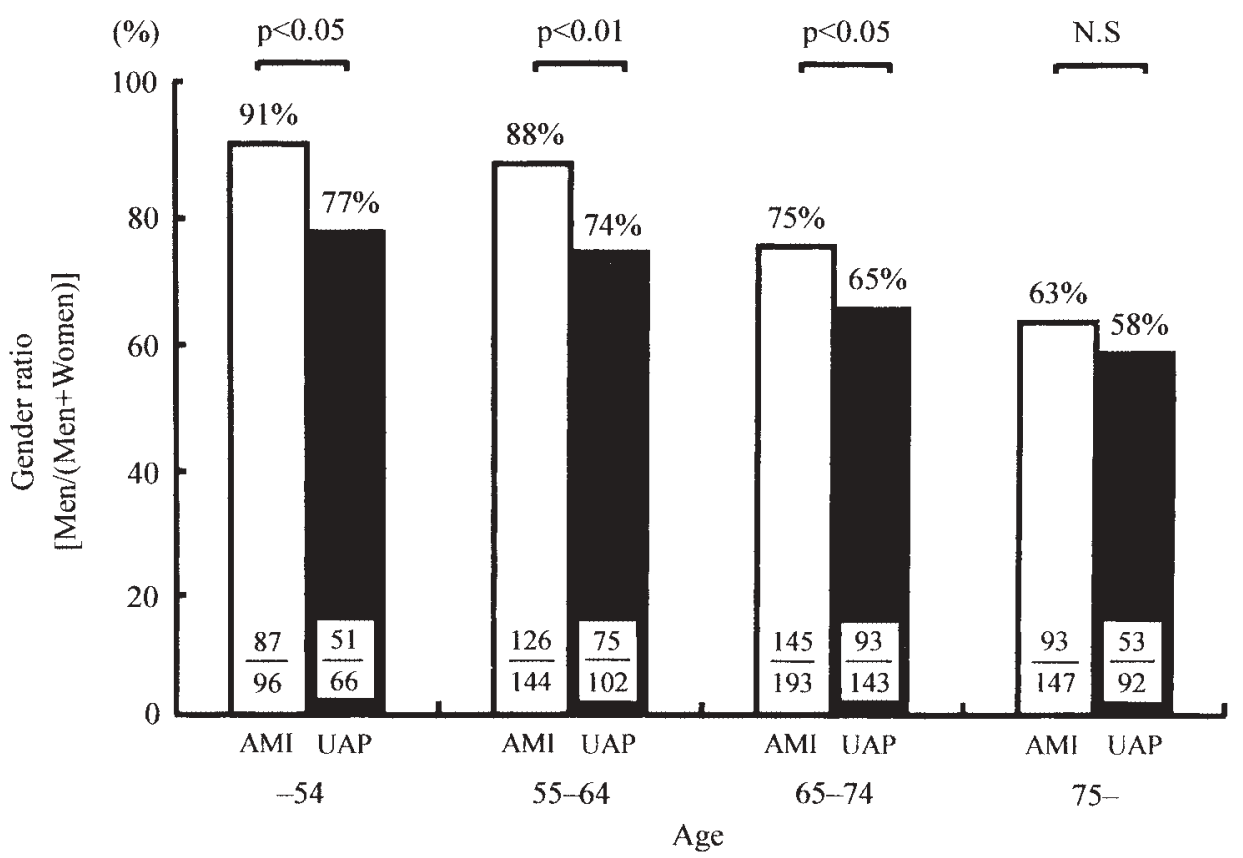

Figure 1. Gender ratio between AMI and UAP. Gender ratio was expressed as the number of the men divided by the total number of the men and the women. The gender ratio was used to evaluate the incidence of AMI and UAP. 
KANAMASA et al

Table 2. In Hospital Prognosis (Death during Hospitalization within 30 Days)

\begin{tabular}{lcccc}
\hline & $\begin{array}{c}\text { AMI } \\
\text { Men }\end{array}$ & $\begin{array}{c}\text { AMI } \\
\text { Women }\end{array}$ & $\begin{array}{c}\text { UAP } \\
\text { Men }\end{array}$ & $\begin{array}{c}\text { UAP } \\
\text { Women }\end{array}$ \\
\hline Cardiac death & $30\left(\begin{array}{c}6.7 \%) \\
\text { Non-cardiac death }\end{array}\right.$ & $16(12.4 \%)$ & $2(0.7 \%)$ & $2(1.5 \%)$ \\
\hline
\end{tabular}

AMI: Acute myocardial infarction, UAP: Unstable angina pectoris, $* \mathrm{p}<0.05$.
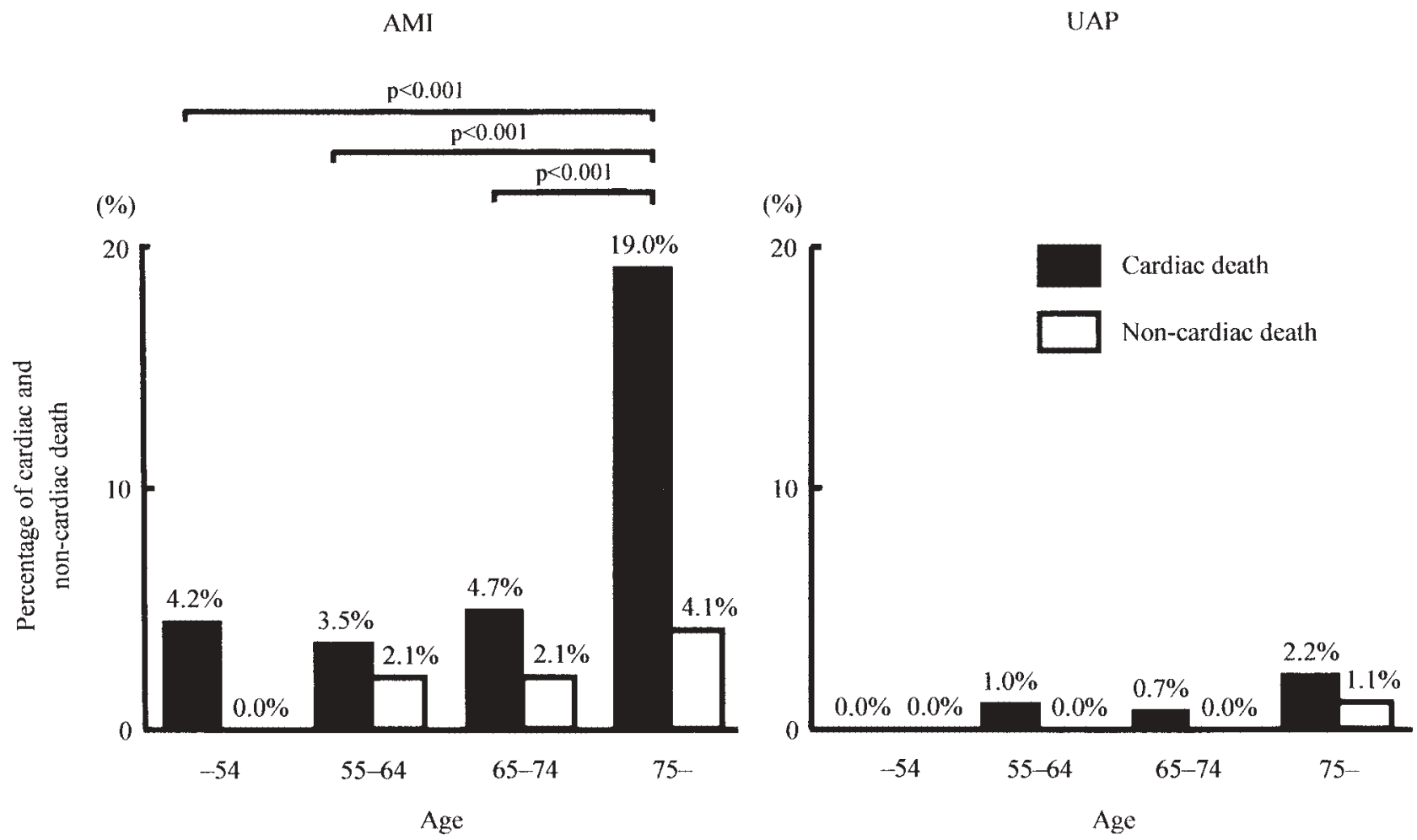

Figure 2. In hospital prognosis in relation to age between AMI and UAP.

75 years old. When age was less than 55 years old, the incidence of the men with AMI was higher than that with UAP (91\% vs $77 \%$, p $<0.05)$; with $55-64$ years old, $(88 \%$ vs $74 \%$, $\mathrm{p}<0.01)$; with $65-74$ years old, ( $75 \%$ vs $65 \%$, p<0.05), however, with 75 years old and over, there was no significant difference between AMI and UAP (63\% vs 58\%, NS).

\section{In-hospital outcome}

The cardiac death during hospitalization within 30 days in AMI was higher in women than in men $(12.4 \%$ vs $6.7 \%$, $\mathrm{p}<0.05)$, on the other hand, in UAP there was no significant difference between women and men $(1.5 \%$ vs $0.7 \%$, NS) (Table 2). In the non-cardiac death during hospitalization within 30 days in both AMI and UAP, there was no significant difference between women and men (AMI: $2.3 \%$ vs $2.2 \%$, NS, UAP: $0.0 \%$ vs $0.4 \%$, NS). Outcome by age of
AMI and UAP during hospitalization within 30 days is shown in Fig. 2. The incidence of cardiac death in AMI was significantly higher in patients 75 years old and over (19.0\%) than in patients less than 55 years old $(4.2 \%), 55-64$ years old $(3.5 \%)$ and $65-74$ years old $(4.7 \%)(\mathrm{p}<0.001$, respectively). There were no significant differences in non-cardiac death among the groups. Percentage of cardiac death and non-cardiac death is shown in Table 3 . When age was 75 years old and over, the incidence of cardiac death in women was 1.5 times higher than men $(24.1 \%$ vs $16.1 \%)$. The proportional hazard approach is a multivariate analysis and uses information from all patients with AMI in the trial. The analysis confirmed that the AMI patients with diabetes mellitus were worse (odds ratio $2.06,95 \%$ confidence interval $1.01-4.19, \mathrm{p}<0.05)$, and AMI patients with severe myocardial infarction (Killip class II-IV) were worse (odds ratio 
Mortality of Acute Myocardial Infarction

Table 3. Percentage of Cardiac and Non-cardiac Death in AMI

\begin{tabular}{cccrrr}
\hline Age & & $\begin{array}{c}-54 \\
(\mathrm{n}=96)\end{array}$ & $\begin{array}{c}55-64 \\
(\mathrm{n}=144)\end{array}$ & $\begin{array}{c}65-74 \\
(\mathrm{n}=193)\end{array}$ & $\begin{array}{c}75- \\
(\mathrm{n}=147)\end{array}$ \\
\hline $\begin{array}{c}\text { Cardiac } \\
\text { death }\end{array}$ & Men & $\begin{array}{r}4 / 87(4.6 \%) \\
0 / 9(0.0 \%)\end{array}$ & $\begin{array}{r}4 / 126(3.2 \%) \\
1 / 18(5.6 \%)\end{array}$ & $\begin{array}{r}7 / 145(4.8 \%) \\
2 / 48(4.2 \%)\end{array}$ & $\begin{array}{r}15 / 93(16.1 \%) \\
13 / 54(24.1 \%)\end{array}$ \\
\hline $\begin{array}{c}\text { Non-cardiac } \\
\text { death }\end{array}$ & Momen & $0 / 87(0.0 \%)$ & $3 / 126(2.4 \%)$ & $3 / 145(2.1 \%)$ & $4 / 93(4.3 \%)$ \\
$0 / 9(0.0 \%)$ & $0 / 18(0.0 \%)$ & $1 / 48(2.1 \%)$ & $2 / 54(3.7 \%)$ \\
\hline
\end{tabular}

PCI

CABG

Smoking

Obesity

CAG at acute phase

Hypertension

ST elevation

CT

Women

History of AP

History of MI

Hyperlipidemia

Diabetes Mellitus

Age (65 years old and over)

Killip class (II-IV)

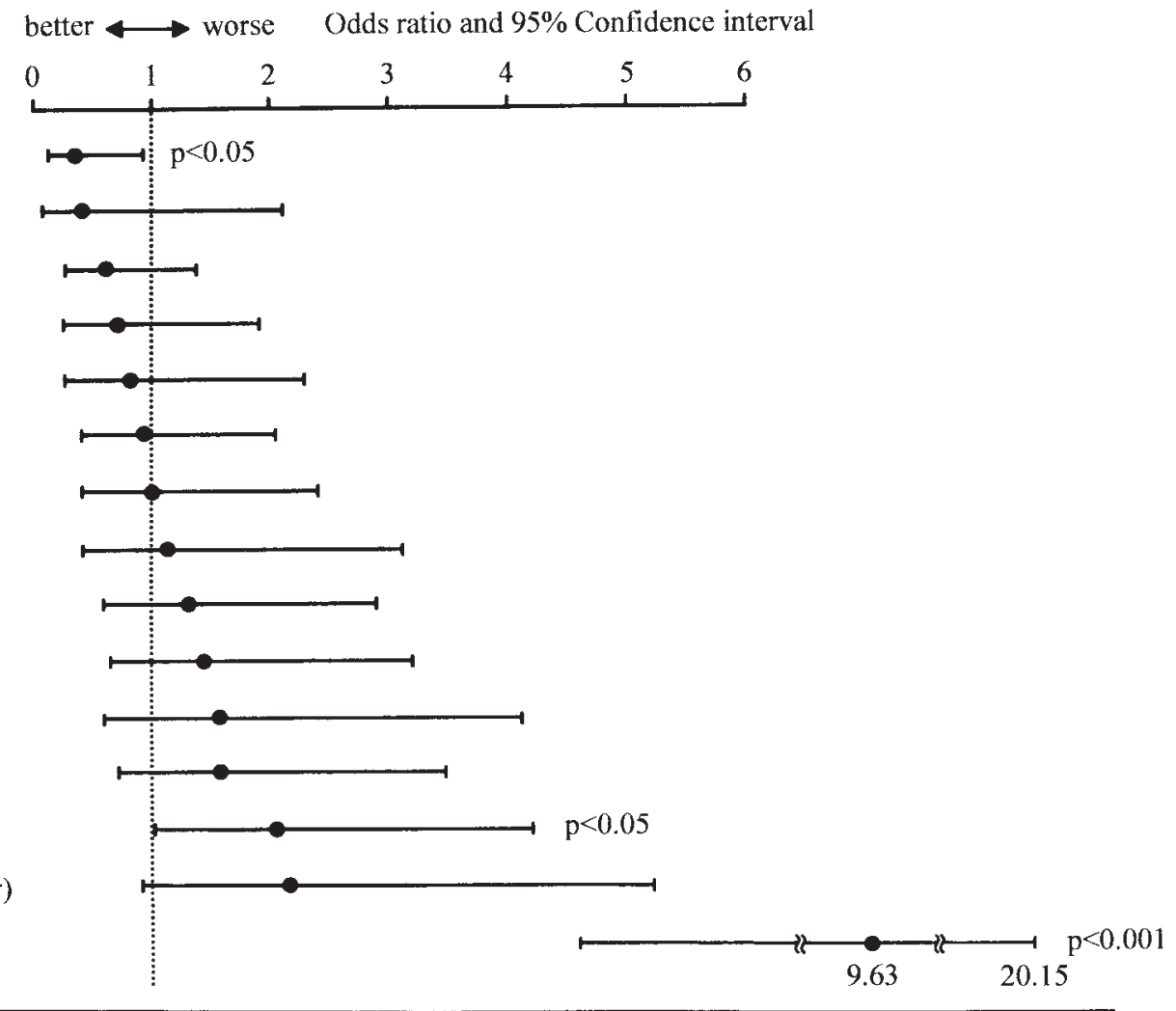

PCI: Percutaneous coronary intervention, CABG: Coronary artery bypass grafting, CAG: Coronary angiography, CT: Coronary thrombolysis, AP: Angina pectoris, MI: Myocardial infarction.

Figure 3. Results of multivariate analysis for predictors of cardiac death during hospitalization within 30 days in patients with AMI.

9.63, 95\% confidence interval $4.60-20.15, \mathrm{p}<0.001)$. The analysis also confirmed that AMI women patients were not independent predictors (odds ratio 1.32, 95\% confidence interval 0.60-2.91, NS) (Fig. 3).

\section{Subgroup analysis}

The characteristics of the patients in AMI men and women patient groups are shown in Table 4. Patients were divided into subgroups based on the occurrence of cardiac death. The incidence of cardiac death was compared in relation to age, risk factors, history of myocardial infarction or angina pectoris, ST elevation, Killip class, coronary angiography at acute phase and treatment. The AMI women patients had a higher cardiac death rate than AMI men patients among patients without obesity $(13.3 \%$ vs $6.5 \%, \mathrm{p}<0.05)$. The AMI women patients had a higher cardiac death rate than AMI men patients with Killip class I (7.6\% vs $1.5 \%$, $\mathrm{p}<0.01)$. In addition, AMI women patients had a higher cardiac death rate than AMI men patients without CABG $(12.4 \%$ vs $6.6 \%, \mathrm{p}<0.05)$. 
KANAMASA et al

Table 4. Subgroup Analysis among Various Backgrounds in Patients with Acute Myocardial Infarction

\begin{tabular}{|c|c|c|c|c|c|c|c|c|}
\hline & & \multicolumn{3}{|c|}{ AMI Men } & \multicolumn{3}{|c|}{ AMI Women } & \multirow{3}{*}{$P$ value } \\
\hline & & \multirow{2}{*}{$\mathrm{N}$} & \multicolumn{2}{|c|}{ Cardiac death } & \multirow{2}{*}{$\mathrm{N}$} & \multicolumn{2}{|c|}{ Cardiac death } & \\
\hline & & & $\mathrm{n}$ & $\%$ & & $\mathrm{n}$ & $\%$ & \\
\hline \multirow[t]{2}{*}{ Age years old } & $<65$ & 213 & 8 & 3.8 & 27 & 1 & 3.7 & \\
\hline & $\geqq 65$ & 238 & 22 & 9.2 & 102 & 15 & 14.7 & \\
\hline \multirow[t]{2}{*}{ Hyperlipidemia } & Yes & 184 & 14 & 7.6 & 64 & 5 & 7.8 & \\
\hline & No & 248 & 14 & 5.6 & 51 & 6 & 11.8 & \\
\hline \multirow{2}{*}{ Hypertension } & Yes & 238 & 18 & 7.6 & 78 & 9 & 11.5 & \\
\hline & No & 194 & 11 & 5.7 & 39 & 4 & 10.3 & \\
\hline \multirow[t]{2}{*}{ Smoking } & Yes & 288 & 12 & 4.2 & 34 & 2 & 5.9 & \\
\hline & No & 123 & 11 & 8.9 & 82 & 10 & 12.2 & \\
\hline \multirow[t]{2}{*}{ Diabetes Mellitus } & Yes & 147 & 15 & 10.2 & 37 & 5 & 13.5 & \\
\hline & No & 289 & 13 & 4.5 & 81 & 8 & 9.9 & \\
\hline \multirow[t]{2}{*}{ Obesity } & Yes & 83 & 5 & 6.0 & 35 & 2 & 5.7 & \\
\hline & No & 352 & 23 & 6.5 & 83 & 11 & 13.3 & $\mathrm{p}<0.05$ \\
\hline \multirow[t]{2}{*}{ History of MI } & Yes & 54 & 7 & 13.0 & 9 & 3 & 33.3 & \\
\hline & No & 376 & 19 & 5.1 & 109 & 8 & 7.3 & \\
\hline \multirow[t]{2}{*}{ History of AP } & Yes & 255 & 12 & 4.7 & 77 & 7 & 9.1 & \\
\hline & No & 156 & 11 & 7.1 & 32 & 4 & 12.5 & \\
\hline \multirow[t]{2}{*}{ ST elevation } & Yes & 93 & 7 & 7.5 & 22 & 4 & 18.2 & \\
\hline & No & 354 & 22 & 6.2 & 102 & 12 & 11.8 & \\
\hline \multirow[t]{2}{*}{ Killip class } & I & 338 & 5 & 1.5 & 79 & 6 & 7.6 & $\mathrm{p}<0.01$ \\
\hline & II-IV & 103 & 24 & 23.3 & 44 & 9 & 20.5 & \\
\hline \multirow[t]{2}{*}{ CAG at acute phase } & Yes & 372 & 22 & 5.9 & 103 & 8 & 7.8 & \\
\hline & No & 75 & 8 & 10.7 & 25 & 8 & 32.0 & $\mathrm{p}<0.05$ \\
\hline \multirow[t]{2}{*}{$\mathrm{CT}$} & Yes & 85 & 5 & 5.9 & 22 & 3 & 13.6 & \\
\hline & No & 360 & 24 & 6.7 & 105 & 13 & 12.4 & \\
\hline \multirow[t]{2}{*}{ PCI } & Yes & 342 & 17 & 5.0 & 89 & 7 & 7.9 & \\
\hline & No & 105 & 12 & 11.4 & 38 & 9 & 23.7 & \\
\hline \multirow[t]{2}{*}{ CABG } & Yes & 34 & 1 & 2.9 & 7 & 1 & 14.3 & \\
\hline & No & 410 & 27 & 6.6 & 121 & 15 & 12.4 & $\mathrm{p}<0.05$ \\
\hline
\end{tabular}

MI: Myocardial infarction, AP: Angina pectoris, CAG: Coronary angiography, CT: Coronary thrombolysis, PCI: Percutaneous coronary intervention, CABG: Coronary artery bypass grafting.

\section{Discussion}

\section{Coronary risk factors with AMI and UAP}

The reasons given for the worse prognosis of women have been older age $(2-6,11)$ more disorders such as diabetes and hypertension $(1-6,11)$, worse hemodynamics (2-6), differences in the time of presentation $(1,12)$, the rates of aspirin and beta-blocker usage $(1,11)$ mechanical complications $(4$, 11), electrical complications $(1,4)$, thrombotic and fibrinolytic activity (13-15), and reduced collateral flow (16). In the present study, the women were older and had a higher rate of obesity, severe grade of Killip class and a lower rate of PCI than the men, but the prevalence of diabetes and hypertension were not different between the two genders.

Panagiotakos et al (17) reported that exposure to cigarette smoke is associated with a significant increase in coronary risk. Yamagishi et al (18) showed that the risk of coronary heart disease was four times higher in current smokers than in never-smokers. Smoking causes direct injury of endothe- lial cells (19), atheroma formation through low high-density lipoprotein (HDL)-cholesterol levels (20), and acceleration of thrombus formation through increased plasma fibrinogen (21), increased platelet aggregability (22), and decreased fibrinolytic activity (23).

\section{In-hospital outcomes with AMI and UAP}

Japanese women with ACS had a higher in-hospital mortality rate than men, and older age is a potential explanation for the higher in-hospital mortality among the women with AMI (24). Several studies have reported that there is no significant difference in the mortality rates between men and women for ACS after adjusting for differences in age and other prognostic factors (3-5). However, several studies have reported that the gender difference in outcome varies among the types of ACS $(6,7)$. Hochman et al (6) reported that among patients with UAP, the women were associated with an independent protective effect. In addition, they reported that the women were older than the men. In Hochman et al 
(6), the women with UAP had a lower rate of 3-vessel disease than the men, which may explain the better outcome for the women in their study. The reason why being a women by itself is an independent predictor of in-hospital mortality in the patients with UAP is unclear, but may relate to poorer myocardial reserve in the women suggested by diastolic dysfunction (7), and reduced collateral blood flow (16). Moreover, the number of leads with ST depression during an anginal attack (25), absence of persistent ischemic chest pain (26), and lack of microvascular reperfusion following revascularization (27) were independent risk predictors of clinical outcome. Japanese women with ACS present with similar angiographic findings and hemodynamics, but have a higher in-hospital mortality rate than male patients. The present results suggest that older age may be a potential explanation for the higher in-hospital mortality in women with AMI, but female gender itself may be an important predictor for it among those with UAP (28).

Multivariate analysis showed that cardiac death was increased in patients with diabetes mellitus and severe grade of Killip class in the patients with AMI. Subgroup analysis showed that AMI women patients had a higher cardiac death rate than AMI men patients in the patients without obesity and without severe grade of Killip class. These data suggest that AMI women patients had a risk for the occurrence of AMI.

In the present study, the cardiac death rate during hospitalization within 30 days in AMI was higher in the women than in the men. When age was with 75 years old and over, the incidence of cardiac death in the women was 1.5 times higher than the men. The incidence of events was higher in AMI than UAP in the patients less than 75 years old between AMI and UAP, however, there was no significant difference in the patients 75 years old and over between AMI and UAP. Epidemiologic data have indicated that the women are relatively spared from coronary heart disease up to the age of 75 (29). Although the reasons for this protection are not entirely clear, estrogen is thought to play a part (30). The pathophysiology of coronary heart disease in premenopausal or middle-aged women may differ from the patients with older women and from men. Plaque erosions are the predominant abnormality in premenopausal women who die suddenly, whereas rupture of plaques is more common in older women and in men (31).

\section{Limitations of the study}

In Japan, the decline in the incidence of cardiac events among post-myocardial infarction patients reflects implementation of new therapeutic modalities (32). Accumulating evidence is clarifying which drugs are effective for secondary prevention for myocardial infarction and which are not (33). We only investigated the profile of AMI and UAP, and outcome during hospitalizations within 30 days. However, these results will contribute to solving the problems of ACS, and also clarify the profile of occurrence in the patients with AMI and UAP in the Japanese population.
In conclusion, the cardiac death rate was higher in women compared with men in patients with AMI. The worse prognosis for the AMI women patients was likely to be derived from less performance of percutaneous coronary intervention, and a high incidence of severe myocardial infarction. Further research should be focused on the analysis of various clinical backgrounds.

South Osaka Acute Coronary Syndrome Study Group (SACS): Kishiwada Tokushukai Hospital; Kinki University School of Medicine; Kishiwada City Hospital; Rinku General Hospital; Osaka Rosai Hospital; Bell Land General Hospital; Shiroyama Hospital; Baba Memorial Hospital; Fuchu Hospital; Osaka Prefectural Habikino Hospital; Osaka Minami National Hospital; Izumi Municial Hospital; Sakai Municial Hospital; Seikeikai Hospital; Teramoto Memorial Hospital; Kinki University Sakai Hospital; Mimihara General Hospital; Kaizuka City Hospital; Asakayama General Hospital; Izumiotsu Municial Hospital; Sakai Onshinkai Hospital; PL Hospital; Tondabayashi Hospital.

\section{References}

1) Vaccarino V, Parsons L, Every NR, Barron HV, Krumholtz HM, for the National Registry of Myocardial Infarction 2 Participants. Sexbased differences in early mortality after myocardial infarction. N Engl J Med 341: 217-225, 1999.

2) Kostis JB, Wilson AC, O'Dowd K, et al and MIDAS Study Group. Sex differences in the management and long-term outcome of acute myocardial infarction. Circulation 90: 1715-1730, 1994.

3) Coronado BE, Griffith JL, Beshansky JR, Selker HP. Hospital mortality in women and men with acute cardiac ischemia: A prospective multicenter study. J Am Coll Cardiol 29: 1490-1496, 1997.

4) Gottlieb S, Harpaz D, Shotan A, et al and Israeli Thrombolytic Survey Group. Sex differences in management and outcome after acute myocardial infarction in the 1990s. Circulation 102: 2484-2490, 2000.

5) Kambara H, Kinoshita M, Nakagawa M, Kawai C, for the Kyoto and Shiga Myocardial Infarction (KYSMI) Study Group. Gender difference in long-term prognosis after myocardial infarction: Clinical characteristics in 1,000 patients. Jpn Circ J 59: 1-10, 1995.

6) Hochman JS, Tamis JE, Thompson TD, et al. Sex, clinical presentation, and outcome in patients with acute coronary syndromes. N Engl J Med 341: 226-232, 1999.

7) Hochman JS, McCabe $\mathrm{CH}$, Stone $\mathrm{PH}$, et al. Outcome and profile of women and men presenting with acute coronary syndromes: A report from TIMI IIIB. J Am Coll Cardiol 30: 141-148, 1997.

8) Report of the Joint International Society and Federation of Cardiology/World Health Organization Task Force on standardization of clinical nomenclature. Nomenclature and criteria for diagnosis of ischemic heart disease. Circulation 59: 607-609, 1979.

9) Myerburg RJ, Castellanos A. Cardiac arrest and sudden cardiac death. in: Braunwald E (eds). Heart Disease, A Textbook of Cardiovascular Medicine. 4th ed. vol. 1, W.B. Saunders Company, Philadelphia, 1992: 756-789.

10) Miettinen O. Estimability and estimation in case-referent studies. Am J Epidemiol 103: 226-235, 1976.

11) Pagley PR, Yarzebski J, Goldberg R, et al. Gender differences in the treatment of patients with acute myocardial infarction. A multihospital, community-based perspective. Arch Intern Med 153: 625-629, 1993.

12) Sheifer SE, Rathore SS, Gersh BJ, et al. Time to presentation with acute myocardial infarction in the elderly: associations with race, sex, and socioeconomic characteristics. Circulation 102: 1651-1656, 2000.

13) Conlan MG, Folsom AR, Finch A, et al. Associations of factor VIII and von Willebrand factor with age, race, sex, and risk factors for atherosclerosis: The atherosclerosis risk in communities (ARIC) study. Thromb Haemost 70: 380-385, 1993. 


\section{KANAMASA et al}

14) Tracy RP, Bovill EG, Fried LP, et al. The distribution of coagulation factors VII and VIII and fibrinogen in adults over 65 years: Results from the Cardiovascular Health Study. Ann Epidemiol 2: 509-519, 1992.

15) Cucuianu M, Lanczek M, Roman S. Plasminogen activator inhibitor (PAI) in obese men and obese women. Rom J Intern Med 31: 183-192, 1993.

16) Johansson S, Bergstrand R, Schlossman D, Selin K, Vedin A, Wilhelmsson C. Sex differences in cardioangiographic findings after myocardial infarction. Eur Heart J 5: 374-381, 1984.

17) Panagiotakos DB, Pitsavos C, Chrysohoou C, Stefanadis C, Toutouzas P. Risk stratification of coronary heart disease in Greece: Final results from the CARDIO2000 epidemiological study. Prev Med 35: 548-556, 2002.

18) Yamagishi K, Iso H, Kitamura A, et al. Smoking raises the risk of total and ischemic strokes in hypertensive men. Hypertens Res 26: 209-217, 2003.

19) Nagy J, Demaster EG, Wittmann I, Shultz P, Raij L. Induction of endothelial cell injury by cigarette smoke. Endothelium 5: 251-263, 1997.

20) Adams RJ, Carroll RM, Nichols FT, et al. Plasma lipoproteins in cortical versus lacunar infarction. Stroke 20: 448-452, 1989.

21) Meade TW, Imeson J, Stirling Y. Effects of changes in smoking and other characteristics on clotting factors and the risk of ischaemic heart disease. Lancet 2: 986-988, 1987.

22) Pittilo RM, Clarke JM, Harris D, et al. Cigarette smoking and platelet adhesion. Br J Haematol 58: 627-632, 1984.

23) Newby DE, Wright RA, Labinjoh C, et al. Endothelial dysfunction, impaired endogenous fibrinolysis, and cigarette smoking. A mechanism for arterial thrombosis and myocardial infarction. Circulation 99: $1411-1415,1999$

24) Oe K, Shimizu M, Ino H, et al. In-hospital outcome in octogenarians with acute coronary syndrome undergoing emergent coronary angiography. Jpn Heart J 44: 11-20, 2003.
25) Saitoh M, Kondoh T, Wakao K, et al. Prognostic significance of the number of leads with ST depression during an anginal attack in high risk patients with unstable angina. Intern Med 41: 270-276, 2002.

26) Kurisu $S$, Inoue I, Kawagoe $T$, et al. Clinical implication of persistent ischemic chest pain on admission in patients with late reperfused acute myocardial infarction. Intern Med 41: 920-924, 2002.

27) Kurisu $S$, Inoue I, Kawagoe T, et al. Diabetes mellitus is associated with insufficient microvascular reperfusion following revascularization for anterior acute myocardial infarction. Intern Med 42: 554-559, 2003.

28) Oe K, Shimizu M, Ino H, et al. Effects of gender on the number of diseased vessels and clinical outcome in Japanese patients with acute coronary syndrome. Circ J 66: 435-440, 2002.

29) Lerner DJ, Kannel WB. Patterns of coronary heart disease morbidity and mortality in the sexes: a 26-year follow-up of the Framingham population. Am Heart J 111: 383-390, 1986.

30) Herrington DM. Sex hormones and normal cardiovascular physiology in women. in: Julian DG, Wenger NK (eds). Women and Heart Disease. Mosby-Year Book, St Louis, 1997: 243-264.

31) Burke AP, Farb A, Malcom GT, Liang Y, Smialek J, Virmani R. Effect of risk factors on the mechanism of acute thrombosis and sudden coronary death in women. Circulation 97: 2110-2116, 1998.

32) Ishikawa K, Kimura A, Taniwa $T$, Takenaka $T$, Hayashi $T$, Kanamasa $\mathrm{K}$, on behalf of the Secondary Prevention Group. Modification of treatment strategies over a period of 14 years has markedly reduced cardiac events among post-myocardial infarction patients. Circ J 66: 881-885, 2002.

33) Ryan TJ, Antman EM, Brooks NH, et al. 1999 update: ACC/AHA guidelines for the management of patients with acute myocardial infarction: Executive summary and recommendations. A report of the American College of Cardiology/American Heart Association Task Force on practice guidelines (Committee on Management of Acute Myocardial Infarction). Circulation 100: 1016-1030, 1999. 